\title{
António Gedeão e Rómulo de Carvalho: A Busca de uma Fonte Comum de Questionamento Entre a Poesia e a CiênCIA
}

\author{
Paulo Nuno Martins*
}

\begin{abstract}
E ste artigo visa ser uma contribuição para o estudo das facetas complementares que encontramos patentes entre a obra de António Gedeão, por um lado, e a obra de Rómulo de Carvalho, por outro, i.e., entre a vida dedicada à ciência, por parte de Rómulo de Carvalho, e o discurso poético-imaginativo da escrita de António Gedeão. O rigor do trabalho, na área das ciências físico-químicas, por parte de Rómulo de Carvalho, é espelhado pela ironia da poesia de António Gedeão.
\end{abstract}

\section{INTRODUÇÃO}

Desde Descartes, com o dualismo corpo-mente, que assistimos à separação das áreas de estudo das ciências exactas, cujo domínio de investigação é o corpo ou a matéria, com o das ciências humanas, cuja área de estudo é a mente. Posteriormente, verificouse o cisma, entre as ciências humanas e as ciências exactas, por parte de Kant. Desde então que esta separação, destes dois universos de inquirição, tem persistido até aos nossos dias. Recentemente, o químico Prigogine [1] propôs uma "nova aliança", entre as ciências exactas (química/física) e as ciências humanas (filosofia/ literatura), (fruto do aparecimento das ciências da complexidade), através da qual poderá advir alguns benefícios para o estudo das ditas ciências exactas, (fruto das reflexões das ciências humanas), como, por exemplo, o que diz respeito ao aprofundamento dos conceitos de realidade (importante, por exemplo, na interpretação filosófica dos paradoxos da Física Quântica), de valores (essencial, por exemplo, no estudo da Bioética), entre outros. Como exemplos, destes dois modos de olhar o mundo e a vida, temos os trabalhos dos químicos e poetas Roald Hoffmann, Primo Levi e Rómulo de Carvalho. De facto, Rómulo de Carvalho, professor, pedagogo, histo-

Centro Interuniversitário de História da Ciência e Tecnologia, Universidade Nova de Lisboa E-mail: paulonuno2003@iol.pt riador e divulgador da ciência, do século XX, veio procurar estabelecer um espaço de conciliação e inter-relação dinâmica entre as ciências exactas, expresso pela actividade de Rómulo de Carvalho, na área das ciências físico-químicas, e as ciências humanas, evidenciado pelo trabalho de António Gedeão, na área da poesia. Diríamos que foi um alquimista contemporâneo, que procurou superar o abismo e o antagonismo que persistia desde Kant, entre estes dois universos de estudo, dando ao ser humano um sentido de maior profundidade, característico dos grandes poetas, que o inspiraram desde tenra idade, como Camões, Cesário Verde, mas também dos grandes professores que ensinaram química, como António Ferreira da Silva (1853-1923), descrito, por Rómulo de Carvalho, como «Homem de ciência e de pensamento».

Neste artigo, de modo a não torná-lo muito extenso, vamos analisar um poema [2, 3], de cada um dos livros, respectivamente, Movimento Perpétuo, Teatro do Mundo, Máquina de Fogo, Linhas de Força, Poemas Póstumos e Novos Poemas Póstumos, tendose como principal objectivo verificar que António Gedeão (através da sua poesia) é o "arquitecto" que esboça e idealiza, através dos seus poemas poético-especulativos, um mundo mais altruísta, justo e fraterno, enquanto que Rómulo de Carvalho (através da ciência) é o "engenheiro" que concretiza no mundo da vida social, como professor, pedagogo e historiador da ciência, os valores do seu "amigo" António.

Contribuição para O Estudo da Obra Multi-Disciplinar de Rómulo de Carvalho e António Gedeão: Alguns Exemplos

Escolheu-se o poema de António Gedeão [4], do livro Movimento Perpétuo, a "Pedra Filosofal", o qual espelha a actividade científica realizada por Rómulo de Carvalho.

Neste poema, António Gedeão escreve: "Eles não sabem que o sonho/é uma constante da vida/tão concreta e definida/como outra coisa qualquer,/ como esta pedra cinzenta/em que me sento e descanso,/.../Eles não sabem que o sonho/é vinho, é espuma, é fermento,/bichinho álacre e sedento,/de focinho pontiagudo,/que fossa através de tudo/num perpétuo movimento./ Eles não sabem que o sonho/é tela, é cor, é pincel,/base, fuste, capitel,/arco em ogiva, vitral,/pináculo de catedral,/ contraponto, sinfonia,/máscara grega, magia,/que é retorta de alquimista,/ mapa do mundo distante,/rosa-dosventos, Infante,/caravela quinhentista/que é cabo da Boa Esperança,/ ouro, canela, marfim,/florete de espadachim,/bastidor, passo de dançal Colombina e Arlequim,/passarola voadora,/pára-raios, locomotiva,/barco de proa festiva,/alto-forno, geradora,/ cisão do átomo, radar,/ultra-som, televisão,/desembarque em foguetão/ na superfície lunar./Eles não sabem, nem sonham,/que o sonho comanda 
a vida,/que sempre que um homem sonha/o mundo pula e avança/como bola colorida/entre as mãos de uma criança.".

Neste poema, a "Pedra Filosofal" (Lápis Philosophorum), António Gedeão procura transmitir uma mensagem de alento, a uma geração reprimida pelo regime ditatorial e atormentada pela guerra (cujo fim se previa difícil), através da escrita simbólica dos "reagentes", que são o sonho e a magia, de modo a obter-se o "produto" final pretendido, uma vida em liberdade e em paz. À semelhança dos antigos alquimistas, que uniam a prática científica (precursora da química) a uma visão humanista da Natureza, a "vida" e "sonho" deixam de ser realidades que se opõem, como acontecia em quase toda a poesia portuguesa até então, para se fundirem, transformando a poesia num facto da vida quotidiana. Neste poema (como em outros), há uma ênfase no vocabulário científicotécnico (característico das suas facetas complementares como poeta e químico), evidenciado, por exemplo, quando escreve: “... cisão do átomo, radar...". Esta busca de uma fonte comum de questionamento relativamente à ciência química está também presente na vida de Rómulo de Carvalho, enquanto professor de físico-química, nomeadamente quando escreveu o livro, de capa preta, intitulado Guia de Trabalhos Práticos de Química [5], indicando os passos para a descoberta de um mundo novo e para a fonte das artes Sagradas, como é a química, quando praticada, como foi o seu caso, com uma consciência de serviço para com os outros. De facto, na sua actividade científica escreveu numerosos livros de divulgação científica, como, por exemplo, a Colecção Ciência para Gente Nova, de que fazem parte, entre outros, A Física para o Povo [6], bem como, Os cadernos de Iniciação Científica como, por exemplo, As Reacções Químicas [7], sendo o objectivo da sua actividade científi$c a$, descrito numa entrevista [8]: "Em relação ao ensino experimental, as experiências acompanham aquilo que queremos ensinar quando estamos na aula, mas o método de ensino não é exclusivamente experimental. As experiências servem para esclarecer o aluno sobre aquilo que está a ouvir.
Eu levava sempre para a aula material que punha em cima da mesa e os alunos olhavam com toda a curiosidade: 'Para que é isto? Para que é aquilo? À medida que ia falando, ia preparando as coisas e mostrando o que se passava, para ilustrar aquilo que estava a dizer.".

Escolheu-se o poema de António Gedeão [9], do livro Teatro do Mundo, "As palavras escolhidas" que reflectem a actividade pedagógica e didáctica realizada por Rómulo de Carvalho.

António Gedeão escreve neste poema: "Não sei, não sei, não sei/não sei, nem ninguém o sabe,/por que este dever me cabe,/dever ou devir, não sei./Outros, que um dia virão,/saberão e entenderão/o que nenhum de nós sabe./Outros dirão o motivo/por que é que me exprimo assim,/por que luto e por que vivo/tão alheado de mim./Por que se impõe, por que oprime/este martírio comum/esta expiação sem crime/na cela de cada um./Por que, sem escolha, me entrego/nas palavras escolhidas,/sementes evoluídas/ cumprindo um destino cego./Tudo então será fácil. Tudo./E todos o entenderão./Todas as gotas deste caudal mudo/no mesmo longo leito correrão./Então se entenderá que a voz do poeta,/ que o metal da trompete e as tintas do antraceno,/que o silvo do motor rasgando o espaço pleno,/que o choque do neutrão da experiência secreta,/que o modo de sentir, de rir, de querer, de amar,/tudo é sinal e símbolo de um coração diferente./E então todos dirão:/Claro! Evidentemente!".

Neste poema, António Gedeão começa por dizer que não sabe a razão de lhe caber um certo dever, descrito nas seguintes palavras: "por que este dever me cabe,/dever ou devir, não sei./.../Por que se impõe, por que oprime/este martírio comum/esta expiação sem crime/.../Por que, sem escolha, me entrego/nas palavras escolhidas,/sementes evoluídas/cumprindo um destino cego./..." e, embora não seja dito explicitamente qual é este dever que lhe impõe um certo martírio, é sugerido (pelo próprio título do poema "As palavras escolhidas"), uma certa responsabilidade pedagógica, que António Gedeão sentia, na escrita da sua poesia, através da qual "denuncia" o "analfabetismo" ou incultura (científica e literária) generalizada, e a acomodação ao "status quo". Tal situação é evidenciada, particularmente, quando o poeta emprega uma ironia feroz no final deste poema, escrevendo: “...Então se entenderá que a voz do poeta,/.../que o modo de sentir, de rir, de querer, de amar,/ tudo é sinal e símbolo de um coração diferente./E então todos dirão:/Claro! Evidentemente!".

Esta busca de uma fonte comum de questionamento em relação à pedagogia está também presente na actividade pedagógica e didáctica de Rómulo de Carvalho, (através da qual procurou, igualmente, "combater" esta incultura), nomeadamente, através da publicação, ao longo da sua vida, de vários artigos didácticos como, por exemplo, "Regras de notação e nomenclatura química" [10], "Novas maneiras de trabalhar com os tubos de Torricelli" [11], "Novo dispositivo para o estudo experimental das leis de reflexão da luz" [12], entre outros, bem como, numerosos artigos de carácter pedagógico como, por exemplo, "A física como objecto de ensino" [13], "Sobre os compêndios universitários exigidos pela Reforma Pombalina" [14], entre outros.

A ironia evidenciada pela poesia de António Gedeão, por um lado, e o desprezo pela ignorância, manifestado pela actividade pedagógica e didáctica, por parte de Rómulo de Carvalho, por outro, é descrito por Diana Andringa [15] numa entrevista: "Pareceu-me um homem frio, de um extremo rigor, sem ilusões, que observava o mundo a partir dos métodos científicos mas que é extremamente afectivo nos seus poemas. Tinha uma personalidade muito contraditória. Conquistava as pessoas não pela simpatia, mas pelo rigor e inteligência. Usava a ironia também para si próprio. Tinha um grande desprezo pela ignorância humana. No fundo, penso que definiu o seu projecto de vida como Galileu, com piedade por todos aqueles que procuram a verdade.".

Escolheu-se o poema de António Gedeão [16], do livro Máquina de Fogo, "Dia de Natal" que evidencia as preocupações sociais de Rómulo de Carvalho. 
Neste poema o poeta escreve: "Hoje é dia de era bom./É dia de passar a mão pelo rosto das crianças,/.../É dia de pensar nos outros - coitadinhos - nos que padecem,/de Ihe darmos coragem para poderem continuar a aceitar a sua miséria,/.../Comove tanta fraternidade universal./É só abrir o rádio e logo um coro de anjos,/como se de anjos fosse,/.../Entoa gravemente um hino ao Criador./E mal se extinguem os clamores plangentes,/a voz do locutor/anuncia o melhor dos detergentes./De novo a melopeia inunda a Terra e o Céule as vozes crescem num fervor patético./(Vossa Excelência verificou a hora exacta em que o Menino Jesus nasceu?/Não seja estúpido! Compre imediatamente um relógio de pulso antimagnético.)/Torna-se difícil caminhar nas preciosas ruas./.../Nas lojas, na luxúria das montras e dos escaparates,/ ...,/as belas coisas inúteis de plástico, de metal, de vidro e de cerâmica./Os olhos acorrem, num alvoroço liquefeito,/.../A Oratória de Bach embruxa a atmosfera do arruamento./.../Mas a maior felicidade é a da gente pequena./.../Cada menino/abre um olhinho/.../Ah!!!!!!!!!!/Na branda macieza/da matutina luz/.../Jesus/o doce Jesus,/o mesmo que nasceu na manjedoura,/veio pôr no sapatinho/do Pedrinho/uma metralhadora./Que alegria/reinou naquela casa em todo o santo dia!/.../Dia de Confraternização Universal,/Dia de Amor, de Paz, de Felicidade,/de Sonhos e Venturas./É dia de Natal./Paz na Terra aos Homens de Boa Vontade./Glória a Deus nas Alturas."

Neste poema a questão central é a dos valores, estando o poeta sedento de mudança de atitudes e de comportamentos. O poeta António Gedeão é um mestre da ironia (cáustica, amargurada, incisiva, inteligente, implacável), empregando-a neste poema de um modo particular, nomeadamente, quando menciona: "Hoje é dia de era bom." e, quando escreve: "...um coro de anjos...", exigidos pelo Natal, alternam com anúncios "...ao melhor dos detergentes..." e, ainda, quando refere: "Vossa Excelência verificou a hora exacta em que o Menino Jesus nasceu?/Não seja estúpido/Compre imediatamente um relógio de pulso antimagnético", bem como, quando escreve: "...veio pôr no sapatinho/ do Pedrinho/uma metralhadora./Que alegria/reinou naquela casa em todo o santo dia!...". Esta ironia é dirigida a uma cultura que valoriza o que é superficial, mundano, através de um consumismo desenfreado, i.e., os sentimentos sublimes como, por exemplo, a paz, o amor são fabricados em série, procurando banalizar-se, assim, os valores de Natal. De facto, apesar da revolução científica ocorrida, durante o século $X X$, verificamos, no entanto, que esta não coincidiu, igualmente, com um aperfeiçoamento das qualidades humanas, tendo-se, pelo contrário, assistido a uma série de barbáries, com um crescente "fosso" entre o conhecimento científico e a existência da humanidade (basta lembrar Auschwitz e Hiroxima ou, ainda, o filme "O Fiel Jardineiro").

Esta busca de uma fonte comum de questionamento em relação às questões sociais está também presente na vida de Rómulo de Carvalho que se pautou pelos valores do seu "amigo" António Gedeão, como, por exemplo, a coerência de vida. Na verdade, Rómulo de Carvalho foi um homem de transição de mundos e paradigmas, entre o regime anterior a 1974 (ao qual não prestou qualquer vassalagem), e o que lhe sucedeu, após a revolução de Abril, (onde não embarcou no percurso fácil dos que usaram as hesitações da jovem democracia para promover a sua carreira pessoal), prezando muito o valor da coerência pessoal.

Escolheu-se o poema de António Gedeão [17], do livro Linhas de Força, "Poema de me chamar António" que espelha a actividade poética de Rómulo de Carvalho.

António Gedeão escreve neste poema: "Hoje, ao nascer do sol, de manhãzinha/ouvi cantar um galo num quintal/quando eu tinha seis anos e fui passar as férias do Natal/com a minha madrinha./Na cama improvisada no corredor/sabiamente fingia que dormia/muito embrulhado num cobertor,/enquanto numa luz melada e quase fria,/o mundo, sabiamente,/fingia que nascia./E então apeteceu-me também nascer,/nascer por mim, por minha expressa vontade,/.../Dobrado em círculo no ventre do meu cobertor,/ enrugado como um feto à espera da liberdade/(viva a liberdade!)/.../Fremiam-se-me as pálpebras sacudindo na luz um pó de borboletas,/.../Cada vez mais feto, mais redondo, mais bicho-de-conta,/.../Foi então que o tal galo cantou./Looooooonge.../Muito looooooonge.../.../Era uma voz redonda, débil, inexperiente,/.../Foi assim que a voz do galo na capoeira/ do quintal da vizinha/.../Chegou e fulminou o meu ser indigente,/ exposto e carecido,/ naquele gesto mole e distraído/do Deus omnipotente/da Capela Sistina/quando ergue a mão terrível e fulmina/o coração/de Adão./E pronto. Eis-me nascido. Cheio de sede e fome./António é o meu nome."

Neste poema o galo é o símbolo da alvorada, i.e., uma metáfora do seu primeiro contacto com a arte das letras, referido no poema: "Hoje, ao nascer do sol, de manhãzinha/ouvi cantar um galo num quintal/quando eu tinha seis anos e fui passar as férias do Natal/ com a minha madrinha./.../fingia que nascia.". No entanto, o nascimento do poeta, propriamente dito, apenas acontece muito mais tarde, em 1956, já com 50 anos de idade, uma vez que António Gedeão considerava que tinha alguma inexperiência na área literária, sendo tal mencionado quando escreve: “...E então apeteceu-me também nascer,/nascer por mim, por minha expressa vontade,/.../Foi então que o tal galo cantou./Looooooonge.../Muito looooooonge.../.../Era uma voz redonda, débil, inexperiente, ...". O poeta "recebe" o nome de António, sendo tal aludido quando refere: "...Chegou e fulminou o meu ser indigente,/exposto e carecido,/naquele gesto mole e distraído/do Deus omnipotente/da Capela Sistina/quando ergue a mão terrível e fulmina/o coração/de Adão./E pronto. Eis-me nascido. Cheio de sede e fome./António é o meu nome.". Este simbolismo da mudança de nome é relevante dentro do contexto deste artigo, tendo em conta que os livros de poesia escritos surgem como tendo sido realizados por outra pessoa, que não Rómulo de Carvalho, de nome António Gedeão, tendo o professor de físico-química e pedagogo, permanecido no anonimato. Mas a mudança de nome é, igualmente, um símbolo, para algumas ordens iniciáticas, de uma missão particular na sociedade. Em 
relação a Rómulo de Carvalho, não sabemos se esta mudança de nome teve um carácter iniciático (para além das características literárias relativas ao pseudónimo, que encontramos, igualmente, em Fernando Pessoa), mas o que se sabe, isto sim, é que esta mudança de nome marca uma actividade, particularmente importante, na vida de Rómulo de Carvalho, como poeta.

Por outro lado, Jorge de Sena [18] sugere que este livro, Linhas de Força, representa um interlúdio entre os livros de poesia anteriores (Movimento Perpétuo, Teatro do Mundo, Máquina de Fogo) e os livros de poesia escritos depois da morte do poeta. Este interlúdio é um espelho das actividades de Rómulo de Carvalho, como sejam, a sua actividade científica, pedagógica e as suas preocupações sociais, por um lado, e a sua actividade como historiador na Academia das Ciências, por outro.

Escolheu-se o poema de António Gedeão [19], do livro Poemas Póstumos, o "Poema do futuro", e o poema [20], do livro Novos Poemas Póstumos, denominado por "Poema do gato", os quais procuram reflectir a actividade como historiador na Academia das Ciências, por parte de Rómulo de Carvalho.

No "Poema do futuro", António Gedeão escreve: "Conscientemente escrevo e, consciente,/medito o meu destino./No declive do tempo os anos correm,/deslisam como a água, até que um dia/um possível leitor pega num livro/e lê,/lê displicentemente,/por mero acaso, sem saber porquê./Lê, e sorri./Sorri da construção do verso que destoa/no seu diferente ouvido;/sorri dos termos que o poeta usou/onde os fungos do tempo deixaram cheiro a mofo;/e sorri, quase ri, do íntimo sentido,/do latejar antigo/daquele corpo imóvel, exhumado/da vala do poema./ Na História Natural dos sentimentos/ tudo se transformou./O amor tem outras falas,/a dor outras arestas,/a esperança outros disfarces,/a raiva outros esgares./Estendido sobre a página, exposto e descoberto,/exemplar curioso de um mundo ultrapassado,/é tudo quanto fica,lé tudo quanto resta/ de um ser que entre outros seres/vageou sobre a Terra."
Este poema faz parte do livro Poemas Póstumos, podendo a palavra póstumo, ser localizada, pelo poeta "vidente", num tempo humano, onde as relações humanas florescerão de um modo mais altruísta. Daí o título, deste poema, ser "Poema do futuro", o lugar histórico, no espaço e no tempo, onde estas relações fraternas se concretizam, tal como é descrito pelo poeta: “... um possível leitor pega num livro/e lê,/.../Lê, e sorri./Sorri da construção do verso que destoa/.../sorri dos termos que o poeta usou/.../e sorri, quase ri, do íntimo sentido,/do latejar antigo/.../ Na História Natural dos sentimentos/ tudo se transformou./O amor tem outras falas,/a dor outras arestas,/a esperança outros disfarces,/a raiva outros esgares./Estendido sobre a página, exposto e descoberto,/exemplar curioso de um mundo ultrapassado,/ de um ser que entre outros seres/vageou sobre a Terra."

Esta busca de uma fonte comum de questionamento, ao nível da história, está também presente na obra de Rómulo de Carvalho, como, por exemplo, quando escreveu as Relações entre Portugal e a Rússia no século XVIII [21], tendo esta obra sido escrita no ano de 1979, altura em que ainda havia uma separação histórica, ideológica e física (evidenciada pelo muro de Berlim), entre os países do Leste e os do Ocidente.

Por outro lado, no "Poema do gato", o poeta escreve: "Quem há-de abrir a porta ao gato/quando eu morrer?/ Sempre que pode/foge prá rua,/cheira o passeio/e volta pra trás,/mas ao defrontar-se com a porta fechada/ (pobre gato!)/mia com raiva/desesperada./Deixo-o sofrer/que o sofrimento tem sua paga,/e ele bem sabe./Quando abro a porta corre para $\mathrm{mim} / \mathrm{como}$ acorre a mulher aos braços do amante./Pego-Ihe ao colo e acaricio-o/num gesto lento/vagarosamente,/do alto da cabeça até ao fim da cauda./Ele olha-me e sorri, com os bigodes eróticos,/olhos semi-cerrados, em êxtase,/ ronronando./Repito a festa,/vagarosamente,/do alto da cabeça até ao fim da cauda./Ele aperta as maxilas,/cerra os olhos,/abre as narinas, e rosna,/ rosna, deliquescente,/abraça-me/e adormece./Eu não tenho gato, mas se o tivesse/quem Ihe abriria a porta quando eu morresse?".

Este "Poema do gato" serve para marcar a clivagem, na cultura contemporânea, entre a "pragmática da criação verbal" (narrativa, poética), e a "pragmática do saber científico". O gato como sentido imediato (e enganador), próprio de uma cultura pós-lluminista que simplisticamente é crente no progresso unidireccional da humanidade, renega o bicho, existindo este apenas como algo virtual. Assim, o gato é um símbolo de uma realidade inexistente, ausente, i.e., o poeta procura transmitir o testemunho de uma ausência de cultura deveras iluminada a operar no âmago da história moderna. A ironia aqui é incisiva e terna ao mesmo tempo, nomeadamente, quando o poeta escreve: “... mas ao defrontar-se com a porta fechada/(pobre gato!)/mia com raiva/.../Quando abro a porta corre para $\mathrm{mim} / . . . /$ Pego-Ihe ao colo e acaricio-o,...". Mas o gato é, igualmente, um símbolo, para diversas culturas (por exemplo, a Egípcia e a Indiana), da vida depois da morte (razão pela qual é associado, por exemplo, às expressões "as sete vidas do gato" ou "a mumificação do gato"). Este simbolismo da vida após a morte, referido em alguns poemas dos livros de poemas póstumos, é relevante dentro do contexto deste estudo, tendo em conta que foram escritos depois da morte do poeta. Por seu lado, Rómulo de Carvalho também alude a este simbolismo da vida depois da morte, nos seus livros Ciência Hermética [22] e Embalsamento Egípcio [23], que reflectem o Mistério da renovação da vida.

Em suma, estes poemas fazem parte dos livros de poesia póstumos, podendo esta palavra ser, igualmente, entendida, como um coroar de toda uma obra, quer ao nível da poesia, quer ao nível da ciência. De facto, em 1974, concluindo 40 anos de actividade docente, como professor e pedagogo, aposentou-se da Função Pública. No entanto, querendo continuar a ser útil à sociedade, após o fim da carreira docente, passou a frequentar mais assiduamente os fundos documentais da Academia das Ciências, tendo elaborado vários livros de investigação histórica como, por exemplo, A actividade pedagógica da Academia das 
Ciências de Lisboa nos séculos XVIII e XIX [24], a primeira de um conjunto de dezasseis obras que publicaria sobre o século XVIII com o patrocínio da Academia. Também na Academia estudou, recuperou e catalogou o material que servira na Aula Maynense, trazendo a público a respectiva colecção de Física, sob o título $O$ material didáctico dos séculos XVIII e XIX do Museu Maynense da Academia das Ciências de Lisboa [25]. Estudou também a colecção de Antropologia da Academia, composta sobretudo por peças colhidas por Alexandre Rodrigues Ferreira (1756-1815), na respectiva viagem filosófica ao Brasil (178392). Enquanto historiador, relacionava com frequência a actividade científica desenvolvida em Portugal com a actividade pedagógica/didáctica, pelo que em 1986 publicou a História do ensino em Portugal [26], obra de referência no estudo do sistema educativo Português. Em 1990 (o mesmo ano do lançamento do livro Novos Poemas Póstumos), Rómulo de Carvalho foi nomeado Director do Museu Maynense, como um reconhecimento do seu trabalho a favor da Academia de Ciências de Lisboa, enquanto que, em 1995, a Universidade de Évora Ihe conferiu o grau de Doutor "Honoris Causa" e, em 1996, a Faculdade de Ciências e Tecnologia, Ihe atribuiu a Medalha de Prata da Universidade Nova de Lisboa. Ainda, em 1996, o Presidente da República atribuiu-lhe, a Grã-Cruz da Ordem de Mérito de Santiago da Espada, enquanto que o Ministro da Cultura agraciou-o com a Medalha de Mérito Cultural, no dia 24 de Novembro, dia Nacional da cultura científica, e data de nascimento de Rómulo de Carvalho, reflectindo a "referência" cultural, para a humanidade, que é Rómulo de Carvalho.

\section{Conclusões}

Rómulo de Carvalho foi uma personalidade singular na vida cultural portuguesa, i.e., a linhagem dos grandes professores do ensino secundário, na área de física e química. Dentro deste seu trabalho foi um grande divulgador da ciência, cujas obras se lêem, ainda hoje, com deleite e proveito, para além de um estudioso da História da ciência em Portugal, em particular no século XVIII.
Estas facetas intelectuais seriam suficientes para the granjear um lugar de destaque entre os seus contemporâneos, mas isto seria ficar no estudo, que se quer completo, de Rómulo de Carvalho, pelo superficial. Poderemos dizer que Rómulo de Carvalho era um refinado alquimista, que desde muito cedo teve contacto com as letras, escrevendo os primeiros poemas aos cinco anos, acrescentando alguns sonetos, aos onze anos, na obra "Os Lusíadas", considerando como uma das suas bíblias "As mil e uma noites", e que culminou com a escrita, já em adulto, entre outros poemas, com a conhecida "Pedra Filosofal". A importância da poesia, na obra global de Rómulo de Carvalho, é notória na formulação de muitos aspectos do seu labor científico. Os seus trabalhos sobre química estão prenhes da visão simbólica alquímica, dos grandes Renascentistas, como é bem expresso, por exemplo, no "Poema do alquimista".

Assim, a biografia de Rómulo de Carvalho [27] ganha uma nova e sugestiva profundidade, quando tratamos, igualmente, dos textos poéticos de António Gedeão. Neste artigo descreveu-se, de um modo sucinto, o carácter marcadamente multi-disciplinar evidenciado por este ser (como historiador da ciência, pedagogo, poeta) que tinha por missão transmitir a luz do conhecimento, científico e literário, aos profanos. Enquanto que a luz do conhecimento científico é transmitida por Rómulo de Carvalho (o seu lado do ser mais extrovertido), já a luz do conhecimento literário é transmitida por António Gedeão (o seu lado do ser mais introvertido), que apenas "nasce" 50 anos depois de Rómulo de Carvalho.

Ao estudarmos o trabalho realizado por Rómulo de Carvalho verificamos que é muito volumoso (tendo sido referido, neste artigo, apenas alguns exemplos): livros sobre História da ciência, livros didácticos, cadernos de iniciação e divulgação científica, artigos pedagógicos e comunicações. Mas ao analisarmos a obra de António Gedeão deparamos, igualmente, com um trabalho de grande profundidade e exigência, que foi expresso, por exemplo, pelos livros de poesia Movimento Perpétuo, Teatro do Mundo, Máquina de Fogo, Poesias Completas [28], Linhas de Força, Poemas Póstumos e Novos Poemas Póstumos.

\section{Agradecimentos}

Ao Professor Doutor António Manuel Nunes dos Santos pelas sugestões na elaboração deste artigo.

Fundação para a Ciência e a Tecnologia, pela Bolsa de pós-doutoramento, SFRH/BPD/63201/2009, atribuída no âmbito deste trabalho sobre História da Ciência.

\section{REFERÊNCIAS}

[1] Ilya Prigogine, A Nova Aliança, Gradiva, 1986.

[2] António Manuel Nunes dos Santos, João Manuel Resina Rodrigues, Christopher Auretta, Uma Tarde com Rómulo de Carvalho e António Gedeão, Faculdade de Ciências e Tecnologia da Universidade Nova de Lisboa, 1986.

[3] António Manuel Nunes dos Santos, Christopher Auretta, António Gedeão, $51+3$ poems and others writings, Faculdade de Ciências e Tecnologia da Universidade Nova de Lisboa, 1992

[4] António Gedeão, Movimento Perpétuo, Coimbra: Atlântida, 1956.

[5] Rómulo de Carvalho, Guia de Trabalhos Práticos de Química, Lisboa, 1957.

[6] Rómulo de Carvalho, A Física para o Povo, volumes I e II, Coimbra, 1968.

[7] Rómulo de Carvalho, As Reacções Químicas, Lisboa, 1980.

[8] Rómulo de Carvalho, jornal Público, 24 de Novembro de 1996.

[9] António Gedeão, Teatro do Mundo, Coimbra: Atlântida, 1958.

[10] Rómulo de Carvalho, "Regras de notação e nomenclatura química", Instituto de Cultura, Lisboa, 1950.

[11] Rómulo de Carvalho, "Novas maneiras de trabalhar com os tubos de Torricelli", Coimbra, 1962.

[12] Rómulo de Carvalho, "Novo dispositivo para o estudo experimental das leis de reflexão da luz", Palestra n²0, páginas 109-113, Lisboa, 1964.

[13] Rómulo de Carvalho, "A física como objecto de ensino", Revista Palestra, n4, páginas 3-10, Lisboa, 1959.

[14] Rómulo de Carvalho, "Sobre os compêndios universitários exigidos pela 
Reforma Pombalina", Miscelânea de estudos dedicados a Joaquim de Carvalho, Figueira da Foz, 1963.

[15] Diana Andringa, revista Visão, n²06, 27 de Fevereiro a 5 de Março de 1997.

[16] António Gedeão, Máquina de Fogo, Coimbra: Atlântida, 1961.

[17] António Gedeão, Linhas de Força, Coimbra: Atlântida, 1967.

[18] Jorge de Sena, A poesia de António Gedeão, Livraria Sá da Costa Editora, 1964.

[19] António Gedeão, Poemas Póstumos, Edições Sá da Costa, 1983.
[20] António Gedeão, Novos Poemas Póstumos, Edições Sá da Costa, 1990.

[21] Rómulo de Carvalho, Relações entre Portugal e a Rússia no século XVIII, Lisboa, 1979.

[22] Rómulo de Carvalho, Ciência Hermética, Colecção Cosmos, 1947.

[23] Rómulo de Carvalho, Embalsamento Egípcio, Colecção Cosmos, 1948.

[24] Rómulo de Carvalho, A actividade pedagógica da Academia das Ciências de Lisboa nos séculos XVIII e XIX, Lisboa, 1981.
[25] Rómulo de Carvalho, O material didáctico dos séculos XVIII e XIX do Museu Maynense da Academia das Ciências de Lisboa, Lisboa, 1993.

[26] Rómulo de Carvalho, A história do Ensino em Portugal, Lisboa, 1986.

[27] Rómulo de Carvalho, O texto poético como documento social, $2^{a}$ Edição, Fundação Calouste Gulbenkian, 2008.

[28] António Gedeão, Poesias Completas: 1956-1967, Portugália Editora, 1968.

\section{Actualidades Científicas}

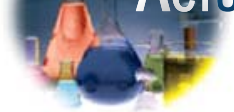

\section{INFRAVERMELHO MAIS RÁPIDO}

Um novo sistema de captação de imagens no infravermelho (IR) baseado em sincrotrão, permitiu aos investigadores a recolha de imagens com a melhor resolução possível (limitada apenas pela difracção da luz) através de todo o espectro IR numa fracção reduzida do tempo correspondente a sistemas de imagiologia IR convencionais (Nat. Methods, DOI: 10.1038/ nmeth.1585).

De facto, a imagiologia química IR requer normalmente um balanço substancial entre resolução espacial e tempo de aquisição de imagem. No entanto, agora "somos capazes de medir rapidamente no limite de difracção em todos os comprimentos de onda" afirma Carol J. Hirschmugl, professora de Física na Universidade de Wisconsin, em Milwaukee, e uma das responsáveis da equipa, acrescentando que "uma imagem que demoraria 11 dias a adquirir, demora agora apenas 20 minutos".

Neste novo sistema, Hirschmugl, Michael J. Nasse, um físico da Univer- sidade de Wisconsin, em Madison, e colaboradores, operaram opticamente 12 feixes do sincrotrão IRENI (IR environmental imaging) num array 3 $\times 4$ que ilumina uma área $50 \times 50 \mu \mathrm{m}$ da superfície das amostras. Desfocaram os feixes de forma a obter uma iluminação homogénea que cobre uma área semelhante à de uma fonte térmica IR convencional, mas que é muito mais brilhante.

Como a intensidade da luz era superior, a equipa pôde utilizar uma objectiva de magnificação muito mais elevada do que as aplicáveis com fontes IR convencionais. Assim, o tamanho efectivo de pixel é de $0.54 \times 0.54 \mu \mathrm{m}$, que corresponde a um centésimo das áreas de pixel de outros sistemas.

"Não esperávamos uma resolução espacial tão elevada como a que obtivemos", confessa Hirschmugl, "penso que é o máximo que se pode obter sem quebrar o limite de difracção".

Trabalhando com Rohit Bhargava, um professor de bioengenharia da
Universidade do Illinois, em UrbanaChampaign, a equipa usou o sistema para obter imagens limitadas pela difracção de amostras de tecidos patológicos da próstata e do peito.

Este trabalho representa um "grande avanço" no desenvolvimento da espectroscopia IR para a imagiologia química, diz Francis L. Martin, investigador no Centre for Biophotonics da Universidade de Lancaster, em Inglaterra. "O trabalho demonstra o que é possivel alcançar na espectroscopia $\mathrm{IR}$, e potencia um novo ímpeto no desenvolvimento futuro de microscópios IR para aplicações de rotina na prática clínica e em laboratórios biológicos.

(adaptado do artigo de 28/03/2011 de Celia Henry Arnaud: Faster, Better Infrared Imaging, Chemical \& Engineering News - http://pubs.acs.org/cen/news/89/ i13/8913notw3.html)

Paulo Brito (paulo@ipb.pt) Instituto Politécnico de Bragança
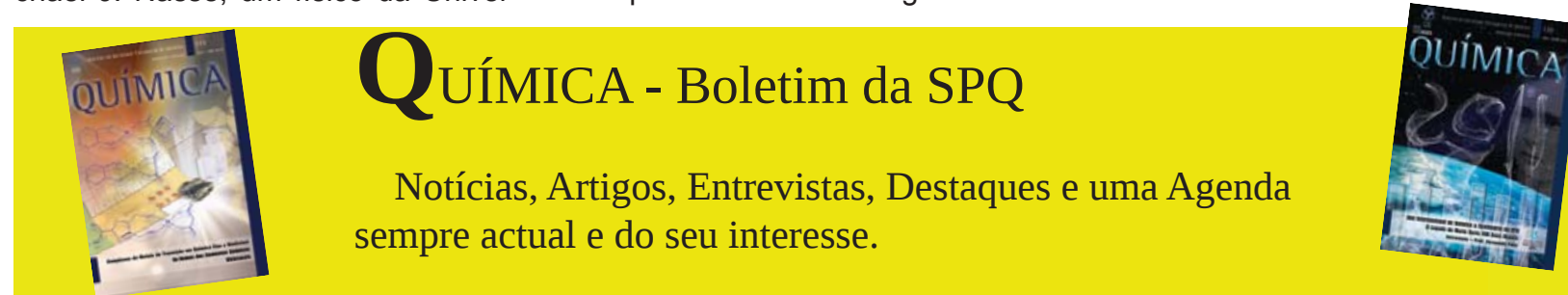